\title{
CRYPTOCURRENCIES FROM ISLAMIC PERSPECTIVES: THE CASE OF BITCOIN
}

\author{
Ahmad Kameel Mydin Meera ${ }^{1}$
}

\begin{abstract}
Cryptocurrencies' popularity has surged during the last few years. This is especially the case of bitcoin, one among cryptocurrencies which price has soared from USD1,000 in the first quarter of 2017 to USD20,000 by the end of 2017. It has now being used by merchants as a medium of exchange. Upon realizing its popularity, the CME Group that owns the Chicago Mercantile Exchange launched a futures contract on bitcoin. Yet, there are cases where bitcoin is banned by the country. This article examines the implication of bitcoin on Islamic finance and questions its acceptance as a medium of exchange (money) based on its compliancy with shari'ah. By analyzing its nature and characteristics, the paper concludes that, strictly speaking, cryptocurrencies that are not backed with real assets are not shari'ah-compliant. However, the majority of shari'ah scholars are leaning towards approving bitcoin on maslahah basis. Bitcoin is neither fiat money nor real money. The absence of an intrinsic value coupled with lack or zero supervision by the central bank will result in misusing bitcoin. Furthermore, we content that it has the elements of maysir and gharar. This can contribute towards socio-economic injustices, thereby jeopardizing the maqasid al-shari'ah. Hence, based on a thorough analysis, we conclude that fiat cryptocurrencies are not shari'ah compliant. However, gold-backed cryptocurrencies are argued to be desirable and consistent with the maqasid al shari'ah.
\end{abstract}

Keywords: Cryptocurrency, Bitcoin, Islamic money, Islamic finance, Shari'ah money, Fintech

JEL Classification: P44, O31

${ }^{1}$ Ceo of Z Consulting Group, Malaysia. Formerly he served as Professor of finance and Dean of the Institute of Islamic Banking and Finance, International Islamic University Malaysia 


\section{INTRODUCTION}

Cryptocurrencies are fast mushrooming throughout the world, particularly since the first worldwide cryptocurrency, bitcoin, was launched in 2009. Initially it did not attract much attention even though the technology behind it is very innovative and advanced. Using cryptography and distributed ledger techniques bitcoin became the first highly secure, non-regulated, global currency that is not issued by any central agency. Hence it is effectively a politically-free money. Lately it has attracted so much interest that just in the year 2017 the price of bitcoin rose from USD 1,000 on $1^{\text {st }}$ January 2017 to USD 20,000 around $18^{\text {th }}$ December 2017, i.e. a momentous increase of $1,900 \%$ within a year. Many reasons are given for this, which we shall discuss later. However, the tremendous interest and success of bitcoin have also caused more such cryptocurrencies to be created and launched. People now see bitcoin and other cryptocurrencies as potentially high return assets. Also more than 100,000 businesses have started accepting bitcoin for payment $t^{2}$. It is the most popular money for use in cryptocurrency e-wallets. Even Islamic finance is looking into ways to embrace this new development. Madina Kalimullina, the economic and finance adviser at Russia Mufti Council remarked recently that halal Islamic cryptocurrencies may soon become a reality (Thedailyeconomist.com, $2^{\text {nd }}$ November 2017).

Observing the tremendous interest and demand for cryptocurrencies like bitcoin, even the CME Group, which owns the Chicago Mercantile Exchange (CME) and the Chicago Board of Trade (CBOT), announced that it would soon launch a bitcoin futures contract by the end of the year (www.cmegroup.com, $30^{\text {th }}$ October, 2017). It indeed launched it. All these developments may not be good news for the US dollar's global hegemony.

The rise in cryptocurrencies, nevertheless, has taken the banking and finance industry by surprise and shock. Being a decentralized money, cryptocurrencies certainly touched the nerves of money issuing central authorities, like central banks of countries. It is indeed a threat to national fiat currencies and to the survival of the banking industry itself. Accordingly, some countries like China, India, and Egypt have resorted to banning bitcoin-based transactions. Bitcoin exchanges were ordered shut down. Nevertheless, cryptocurrencies which are new fintech products, are indeed disrupting global money, banking, and finance. Many have embraced them while others are still resisting them.

But what are the views regarding cryptocurrencies, like bitcoin, from Islamic money and finance perspectives? Does bitcoin, for example, fulfill the criteria for Islamic money? Will Islamic and shari'ah scholars embrace cryptocurrencies? This paper attempts to answer those questions. Section 2 discusses what cryptocurrencies are and its underlying blockchain technology. Sections 3, 4, and 5 discuss the concept of money, Islamic money, and payment systems. Sections 6 and 7 analyze bitcoin from the concept of money and Islamic perspectives. Lastly, section 8 provides the final contentions and conclusion.

2 en.wikipedia.org 


\section{CRYPTOCURRENCIES}

A cryptocurrency is a digital money that is made highly secure using some leadingedge cryptography technology. It secures the issuance of the digital money, its transfers and its historical chronological transactions record. Bitcoin is currently the most popular cryptocurrency.

Bitcoin uses cryptography for the issuance of new digital coins and uses the blockchain technology to record transactions and store them in all the networknodes (computers, laptops, mobiles etc.) throughout the world in a distributed ledger called blockchains, i.e. without any central data storage. While cryptography has been around for quite some time now, it is the blockchain technology that is considered an innovation in computer science. This technology is indeed disrupting many ways how human beings organize their economic interactions. All transactions are transparent, verified, grouped together, and stored in many locations.

Therefore, the bitcoin system is a global digital money, an e-payment system, and a public ledger, all in one. It's a peer-to-peer system, managed collectively, with high transparency. It, therefore, entails direct transactions between users without any intermediary like banks or other financial institutions. As such it is not centrally issued and it has no single administrator or regulator. Transactions are verified by the network nodes and recorded in a distributed ledger. These make bitcoin a highly secure money and payment system.

In the bitcoin network, say $X$ wants to buy an iPhone from $Z$ for $0.1 \mathrm{BTC}^{3}$. $\mathrm{X}$ would send a message to the network indicating his wish to transfer $0.1 \mathrm{BTC}$ to $\mathrm{Z}$. He would provide his own and Z's account numbers, the amount to be transferred, his digital signature and a proof that he actually has the required BTCs. This is done using private keys and public keys that are secured through cryptography.

The private key is used by the participant to initiate a transaction by issuing both his digital signatures and public keys that would allow others in the network to verify information and permit the execution of the requested transaction. This request would be floating in the network until someone in the network pick it up for verification and validation. These people are called miners and they verify the digital signature and the proof of funds. Once verified and approved, the transaction executed and stored in a digital block.

A block consists of a number of verified, chronologically ordered transactions that took place within a time span, say about 10 minutes. Verifying transactions chronologically prevents double spending of funds. The miners, thereafter, would compete to find the cryptography hash-key ${ }^{4}$ that would lock the block, for which the miner who found it would be rewarded with bitcoins. This is how bitcoins originate $^{5}$.

3 BTC is the currency symbol for bitcoin.

4 This cryptography hash-key is formed through some complex mathematical formula that is a function of the information contained in the block.

5 Others can obtain bitcoins by selling goods or services for bitcoins or buying them from a cryptocurrency exchange using national currencies. 
In short, the blocks are time-stamped, locked and interlinked, all using cryptography. To change a record in a particular block, for example, one would have to find the cryptography keys for all the locks from the latest block up till that intended block, and complete the desired changes before a new block is added by anyone in the network. Moreover, altering records will also alter the cryptographic locks of that block and all subsequent blocks. This unique structure makes information in the block practically irreversible. It is this irreversibility of data in blockchain technology that is considered as an innovation and a significant contribution to the field of computer science. In summary,

Blockchain is decentralized database that stores registry of assets and history of transactions across a peer-to-peer network, i.e. on every computer in the network. It is therefore a Public Registry of who owns what and who transacted what. Transactions are secured through cryptography and over time the transactions history is locked in blocks of data that are cryptographically linked together and secured, i.e. immutable, unforgeable, hard to temperwith...Blockchain can record not only money, like bitcoin, but many other kinds of assets too - history of custodianship, ownership, location of assets, title of ownership, a certificate, a contract, real objects, personal identifiable information etc...[It is therefore,] a revolution in the way money, assets and securities are stored, transferred, accounted for and reconciled.

Bettina Warburg, TEDTalk

Hence to recap, bitcoins are created through a reward mechanism called mining. In order to obtain a bitcoin, sophisticated mathematical problems need to be solved, that gets more and more difficult over time. Bitcoin is not backed by any asset, i.e. not redeemable for any tangible asset. The maximum number of bitcoins is apparently limited to 21 million coins only. About 16,000,000 bitcoins have already been issued by November 2017. See Diagram 1 below.

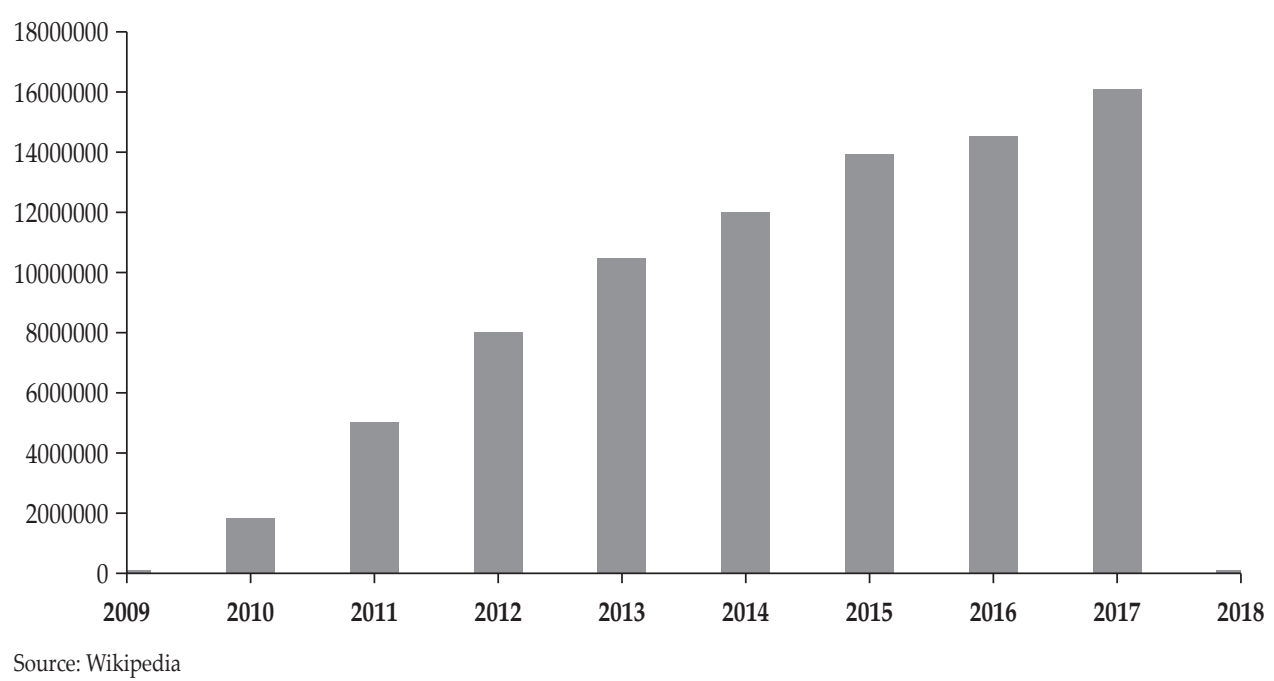

Diagram 1. Total Number of Bitcoins in Circulation 
Some cryptocurrencies are, however, also backed by real assets, like gold. These are issued by private parties. One such cryptocurrency is OneGram that was issued in Dubai recently. Table 1 below gives a comparison between fiat national currencies and cryptocurrencies, both asset-backed, and unbacked ones.

Table 1.

Comparison between Fiat Currencies and Cryptocurrencies

\begin{tabular}{|c|c|c|c|}
\hline & Usual Fiat Currencies & $\begin{array}{c}\text { Cryptocurrencies } \\
\text { Not Backed by Real } \\
\text { Assets }\end{array}$ & $\begin{array}{l}\text { Cryptocurrencies } \\
\text { backed by Real } \\
\text { Assets, like Gold }\end{array}$ \\
\hline Asset Backed? & No & No & Yes \\
\hline Examples & $\begin{array}{l}\text { National currencies } \\
\text { notes, coins, e-money, } \\
\text { like ringgit }\end{array}$ & Bitcoin & OneGram \\
\hline Issuer & $\begin{array}{l}\text { Central authorities } \\
\text { like central banks and } \\
\text { commercial banks. }\end{array}$ & $\begin{array}{l}\text { Issued by the system to } \\
\text { Private individuals for } \\
\text { performing some task. } \\
\text { Not issued by central } \\
\text { authorities. }\end{array}$ & $\begin{array}{l}\text { Private issuers. Not } \\
\text { issued by central } \\
\text { authorities like central } \\
\text { banks but the issuer is } \\
\text { known. }\end{array}$ \\
\hline $\begin{array}{l}\text { Secure } \\
\text { from Counterfeit? }\end{array}$ & Low & High & High \\
\hline Asset or Liability & Liability of the Issuer & $\begin{array}{l}\text { Not a liability of anyone. } \\
\text { A new Asset Class }{ }^{6}- \\
\text { Digital Asset }\end{array}$ & Real Asset \\
\hline Regulator & Central Bank & No Regulator & $\begin{array}{l}\text { No regulator but } \\
\text { members abide by rules } \\
\text { commonly set or by the } \\
\text { operator }\end{array}$ \\
\hline Guarantor & $\begin{array}{l}\text { Government is the } \\
\text { guardian and protector } \\
\text { of the money and } \\
\text { monetary system }\end{array}$ & $\begin{array}{l}\text { No ownership of system } \\
\text { and no guarantor. } \\
\text { Highly risky and } \\
\text { uncertain }\end{array}$ & $\begin{array}{l}\text { Guaranteed by system } \\
\text { owners or operator. } \\
\text { There is system } \\
\text { ownership and rules. }\end{array}$ \\
\hline
\end{tabular}

Source: Author

In order to evaluate cryptocurrencies from Islamic perspective it would be wise to review our knowledge on money and its functions in Islam.

\section{WHAT IS MONEY?}

It is common knowledge that mankind invented money to initially solve the two problems associated with barter exchanges, i.e. 1) The double coincidence of wants, and 2) The indivisibility of items of exchange. Hence societies introduced

${ }^{6}$ CME Group's Chairman Emeritus, Leo Melamed, sees bitcoin likely becoming a new asset class in its own right and be traded in a regulated market soon. Reuters 7 November, 2017. 
money into their markets and business transactions basically to address those two problems. A society could practically use anything that they can agree upon as money. Bernard Lietaer in his classic book The Future of Money, defines money as below.

Money is an agreement, within a community, to use something as a medium of exchange.

Hence, they could practically use anything as money. This money-agreement is observed historically made freely or coerced, formally or informally, and even consciously or unconsciously. Most Islamic and shari'ah scholars too seem to agree with such definition of money. Whatever a society takes as money, so long the item is a halal item, shari'ah scholars seem to approve it based on the concept of maslahah, and hence the rules of as-sarf and riba are applied upon it. All subsequent Islamic business contracts and exchanges and finance would then be based on that 'money' which the society has agreed upon. In other words, money is taken as given and, therefore, subsequent contracts, discussions, and deliberations on shari'ah issues do not question the nature of money. In this regard, mankind has used various commodities and materials as money, for example cowry shells, leather, gold, silver, wheat, salt, etc. Later, fiat money like national paper currencies and electronic money came into the picture. Now we see the interesting phenomenon of cryptocurrencies where these are neither issued by central authorities nor even regulated.

Nonetheless, over time, societies discovered that for an item to play an effective and efficient role as money, it must meet certain requirements:

1. Accepted - the item must be desired for its own sake, i.e. having intrinsic value

2. Divisible - it must be easily divisible into smaller units

3. Homogenous - it must be uniform so that is easily divisible

4. Durable - it has to be long lasting and not easily destroyed

5. Mobile - it lends itself to be easily carried around

6. Rare - this allows a small quantity of it to have a large value

7. Stable value - it has a stable value relative to other things, particularly those naturally occurring things

The first criterion, "Acceptance" is tricky. In most cases of today, the acceptance of money having no intrinsic value is forced upon the people by governments through the legal tender law.

An item having at least the first five characteristics makes it good money. Having the additional last two makes the item excellent money. Societies have used many items in the past, that have the above criteria, as money including cowry shells, beads, and items mentioned in a hadith of the Prophet (peace be upon him) regarding ribawi items, i.e. gold, silver, wheat, barley, salt and dates, etc. Societies have similarly evolved to use paper currencies, coins, cheques, electronic money, and now cryptocurrencies as money. Note that all those items fulfill most of the above- mentioned criteria. Saidina Umar r.a. is said to have apparently wanted to use camel skin as money, which also in a way fulfills the above criteria, but was short of implementing it apparently for fear that people might start killing or stealing camels in order to create money. Nonetheless, any item chosen by the 
society as money would then automatically would fall under the rules of as-sarf and riba.

However, Abdullah (2016) noted that most of the general items mentioned above were referred to as wasilat at-tabadul, or a wider medium of exchange by the notable classical Islamic scholars like Al-Mawardi, Abu Ubayd, Al-Ghazali, Ibn Khaldun, and Al-Maqrizi, relative to their unanimous preference and definition of the dinar and dirham as an-Nuqud al-Islamiyyah, i.e. Islamic money. On top of playing the normal funtions like medium of exchange, unit of account, standard of deferred payment and store of value, money in Islam is also used as a standard in shari'ah legal requirements of 1. Zakat (poor tax); 2. Jizya (tribute tax); 3. Kharaj (tax on conquered territory); 4. Diyat (blood-money); 5. Sariqa (theft); 6. Mahar (dowry); and 7. Sarf (currency exchange).

\section{ISLAMIC MONEY AND THE ‘STORE OF VALUE' FUNCTION}

Is there such a thing as "Islamic money"? When we say something is 'Islamic', it means that something contributes to the attainment of the maqasid al shari'ah. If something causes a movement away from the attainment of the maqasid al shariah, we say that thing is 'unislamic'. Therefore Islamic economics, Islamic banking and finance, etc must contribute towards attaining the maqasid al shari'ah. Hence if there is an item that can help society attain some of the objectives of shari'ah, then that item is 'Islamic'. Accordingly, if there is a money or payment system that can assist us in the attainment of the maqasid al-shari'ah, we may term that as Islamic money and payment system and vice-versa.

In this respect, the store of value function is crucial because if money fails to preserve its value reasonably well in the long run then that would jeorpardize the maqasid al-shariah, particularly the protection of wealth (hafiz al-mal) function. If people save money for the future but the value of money keeps depreciating over time, then people would lose that money wealth in time. This is counter to the maqasid al-shariah. Hence it is of paramount importance that an islamic money plays the 'store of value' function well. The store of value function is indeed a litmus test as to the validity of a medium of exchange in Islamic economics and finance (Abdullah, 2016).

\section{DESIGNING AN ISLAMIC MONEY AND PAYMENT SYSTEM}

From the foregoing discussion, the first and foremost thing in designing an Islamic money and payment system is for the society to decide on the Reference Material, i.e. what item to use as a measure of value in socio-economic interactions. It is imperative and unavoidable that the Reference Material must be something real ${ }^{7}$ and fulfill the criteria of money discussed section 3 earlier, at least the first five

7 The reference material must have its own intrinsic value in the sense that utility can be potentially derived from it, either in the form of non-destructible utility as in gold and silver since their use is more of ornamental, or destructible utility as in commodities like dates, wheat, air-time etc. since these are destroyed in the process of consumption. 
criteria or best all the seven (Please see Diagram 2 below). This reference material necessarily will have to be some kind of commodity or some standardized service $^{8}$. The reference material is of paramount importance in order to eliminate seigniorage and all its socio-economic negative effects so that the maqasid al-shari'ah is not jeopardized. In other words, there exists a direct link between this Reference Material and "monetary justice" in the economy.

Once the Reference Material has been decided, then a certain quantities of it are then identified as units of money. For example, classical Islamic societies have decided upon using gold and silver as the Reference Material and used $4.25 \mathrm{gm}$ of pure gold as dinar and $3 \mathrm{gm}$ of silver as a dirham, i.e. as reference units. These standardized coins of monetary units then circulate as money in the society. For modern applications, including e-money, these quantities may also be used as the standard monetary units.

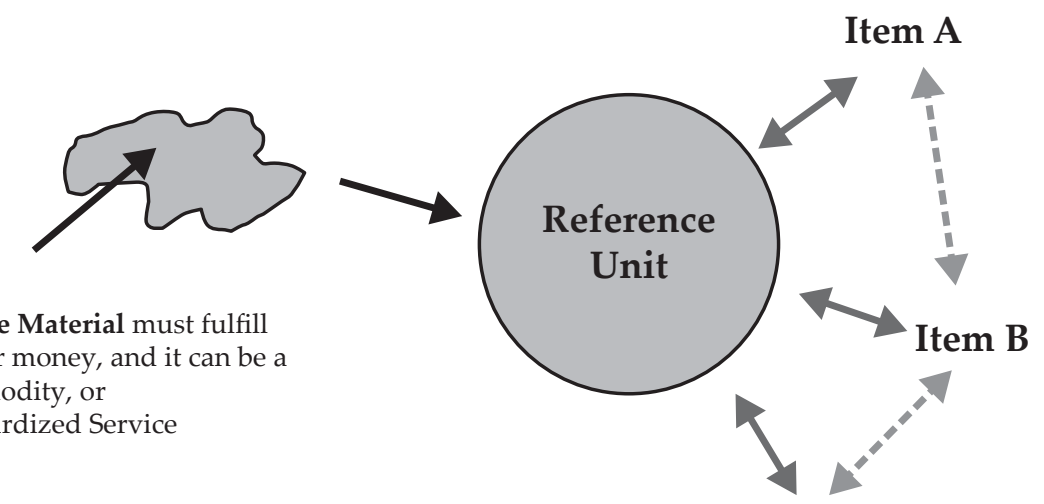

\section{Item C}

Diagram 2. Money as Medium of Exchange (Commodity) and as Unit of Account or Measure of Value (Information) ${ }^{9}$

$\longleftrightarrow$ When the Reference Unit, like gold dinar, is used for, say, buying item A, then it is being used as a medium of exchange. Here money is a commodity and being exchanged for another real thing. It is effectively like a barter exchange and a fair transaction because both of the items exchanged have intrinsic value.

$\leftrightarrow$ When the Reference Unit like gold dinar is used for pricing, say item A and item $B$ as being one dinar, then it is being used as a measure of value or unit of account. Hence A and B can be exchanged directly without using gold dinar at all. Here, money is INFORMATION.

8 Like mobile air-time as in the case of M-Pesa in Kenya

9 K. M., and Mubasheera, Hamida. (2015). Revisiting the Concepts of Money, Profit and Interest from the Perspective of Value and Diminishing Marginal Utility. Journal of Islamic Monetary Economics and Finance, 1(1), pp. 25-53. 
Nyazee (2008) ${ }^{10}$ illustrates the concept of riba as derived and expounded by the classical scholars. The learned professor concluded as follows:

The truth is that if the strict legal position of Islamic law is adopted, all transactions in paper currency [fiat money] will become invalid.

Nyazee, Imran K. (2008) The Concept of Riba and Islamic Banking Advanced Legal Studies Institute, p129

Analyzing Nyazee (2008), one can deduce that four types of payment methods are permissible in Islamic muamalat. These are illustrated in Diagram 3 below:

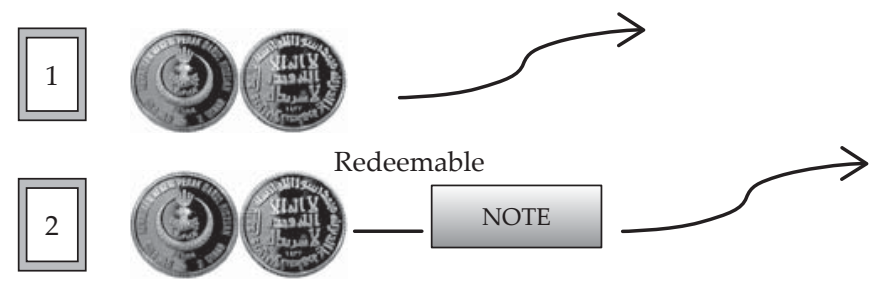

Paper notes, electronic etc.

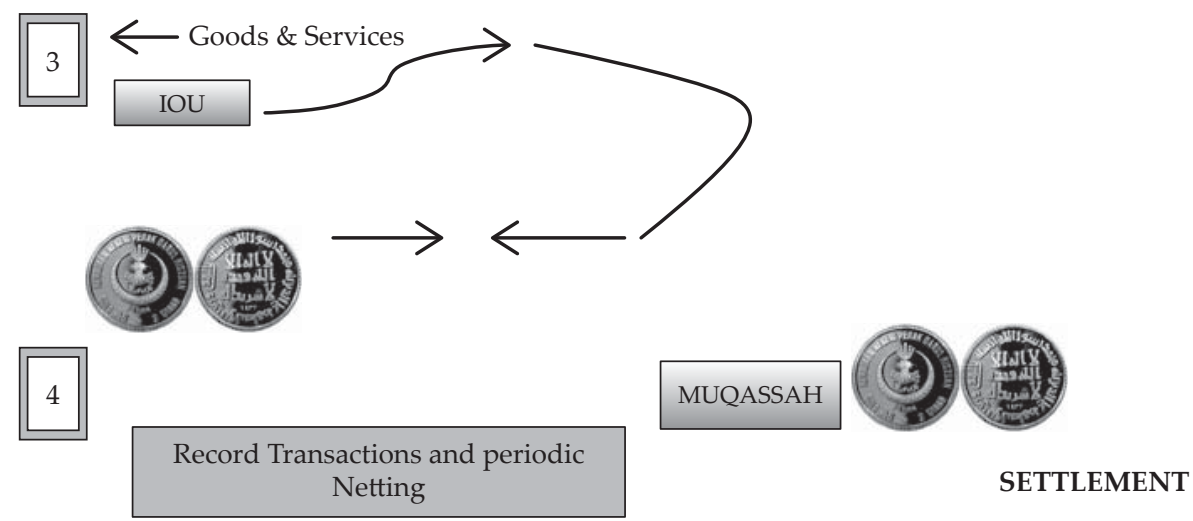

Diagram 3. Four Types of Permissible Payment Methods

In Diagram 3, the $1^{\text {st }}$ permissible transaction is quite straightforward. One has the Reference Unit that is made of the Reference Material, for example a gold dinar and exchanges it for goods and services. This is a direct fair transaction. In the $2^{\text {nd }}$ case, one has a redeemable note as money. The note, which is representative money, is redeemable for a gold dinar, for example, from the issuer of the note. The

${ }^{10}$ Nyazee, Imran K. (2008). The Concept of Riba and Islamic Banking. Advanced Legal Studies Institute. 
note simply eases transactions by being easy to be moved about and is effectively similar to the $1^{\text {st }}$ transaction. The $3^{\text {rd }}$ case is where goods and services are purchased on a credit basis by issuing an IOU for a certain period, say 1 month.

The IOU can be circulated as money in the society and whomsoever holding it at the end of the month can then redeem it, for a gold dinar for example, from the issuer of the IOU. In this case, however, it is not permissible to circulate an IOU as money if it originated from a monetary loan. This is easily reasoned because if that were allowed, then both the loaned-money and the IOU would circulate as money, thereby putting inflationary pressures on the economy. The final $4^{\text {th }}$ case is where all transactions are simply captured in an accounting ledger, i.e. debits and credits, among the participants but then periodically net-off and balances settled among the participants using the Reference Units, i.e. gold dinars in this example. This netting off and settlement is call muqassah in shari'ah, and is permissible. Those are effectively the four permissible money transactions or payment methods allowed in shari'ah, that are devoid of riba, as deduced from Nyazee (2008). Having discussed the characteristics of good money and Islamic money/payment methods, let's analyze if bitcoin has these characteristics.

\section{DOES BITCOIN HAVE GOOD-MONEY CHARACTERISTICS?}

From the foregoing discussion, this section analyzes bitcoin from the Islamic money and payment methods perspective. First of all, does bitcoin fulfill the seven criteria for good money? This is summarized in Table 2 below.

Table 2.

Does Bitcoin Fulfill The Good Money Criteria?

\begin{tabular}{|c|c|c|c|}
\hline & Criteria & Remarks & \\
\hline 1 & Accepted & $\begin{array}{l}\text { It is quite accepted by people on their own free will even though it has no } \\
\text { intrinsic value }\end{array}$ & $x$ \\
\hline 2 & Divisible & Being an electronic currency, it is easily divisible & $\sqrt{ }$ \\
\hline 3 & Homogenous & Being electronic it is effectively homogenous & $\sqrt{ }$ \\
\hline 4 & Durable & $\begin{array}{l}\text { Being stored as electronic bytes in a distributed ledger, it is highly } \\
\text { durable }\end{array}$ & $\sqrt{ }$ \\
\hline 5 & Mobile & Being electronic, it is highly mobile & $\sqrt{ }$ \\
\hline 6 & Rare & $\begin{array}{l}\text { The issuance of bitcoin is through a mining process that makes bitcoin } \\
\text { rare }\end{array}$ & $\sqrt{ }$ \\
\hline 7 & Stable Value & $\begin{array}{l}\text { Lately the value of bitcoin has been fluctuating rather 'violently' i.e. } \\
\text { depicting high volatility }\end{array}$ & $x$ \\
\hline
\end{tabular}

Hence it is clear from the above Table 2 that bitcoin fulfills at least five of the seven criteria, except for two criteria; it is accepted for its own intrinsic value and it has a stable value. Bitcoin has no intrinsic value and its monetary value is not stable (See Figures 1 to 3 ). Note that having a stable value, i.e. being a good store of value, is a litmus test for shari'ah money, so that it can function as a protector of wealth, which is one of the maqasid al-shari'ah. Without having intrinsic value, the element of economic injustice would creep in, through the seigniorage of fiat 
money. Also note that without intrinsic value, or having 'ain', it does not fall into any of the four permissible money transactions deduced from Nyazee (2008). In other words, it has no Reference Material.

However, since bitcoin is accepted by thousands of merchants throughout the world, it is therefore, still 'money' by modern definition of it and shari'ah scholars are likely to approve it and make it subject to the rules of as-sarf and riba. Nonetheless, countries that aspire to 'control' its people are likely to ban bitcoin and other cryptocurrencies since these bypass monetary authorities in terms of their creation and transfers.

\section{ANALYSIS OF BITCOIN, A FIAT CRYPTOCURRENCY, FROM ISLAMIC MONEY PERSPECTIVES}

We have established that a cryptocurrency like bitcoin is indeed money so long a group of subjects like individuals and merchants accept it for payment among themselves. It is no different from normal e-money (which is also fiat money) except that it is not centrally issued and neither regulated nor guaranteed by any authority. However, the following further issues and observations are noted regarding bitcoin.

First of all, the price of bitcoin has been soaring lately. Just in 2017 its price has increased by more than 1,900\%, from a USD1000 per bitcoin to USD20,000 by mid-December (Figure 1 below). Also the price has been highly volatile (Figure 2 below).

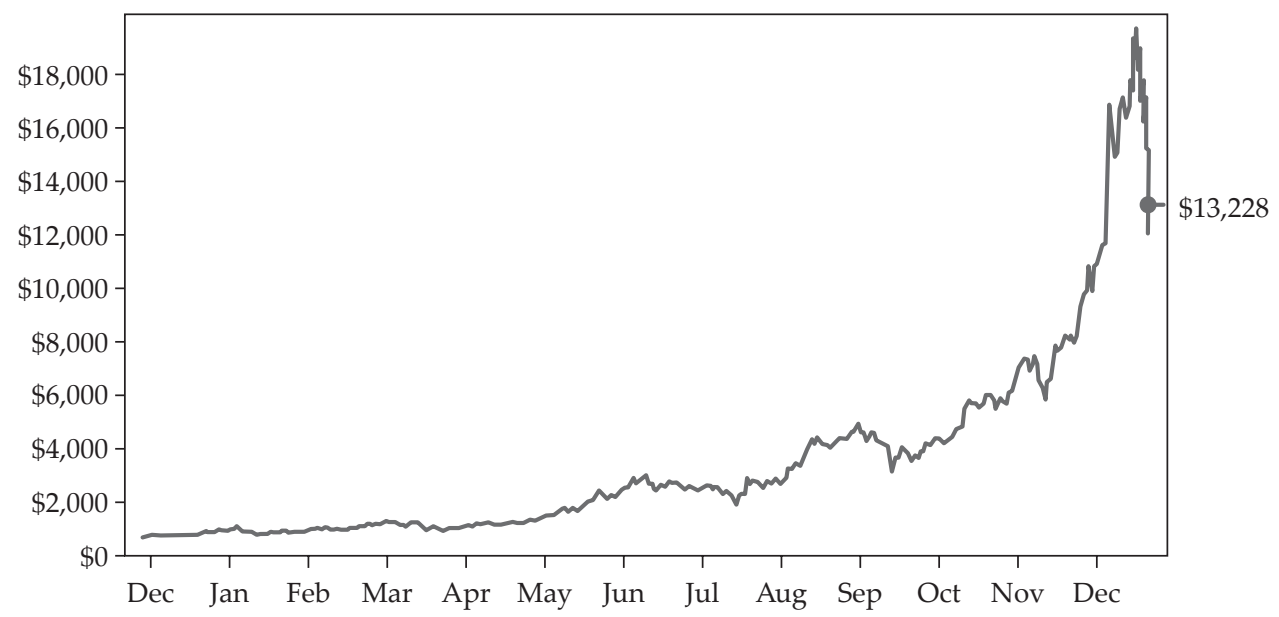

Source: Coindesk.com

Figure 1. Bitcoin Value, Jan 1 - Dec 22, 2017 
Standard deviation of daily retums

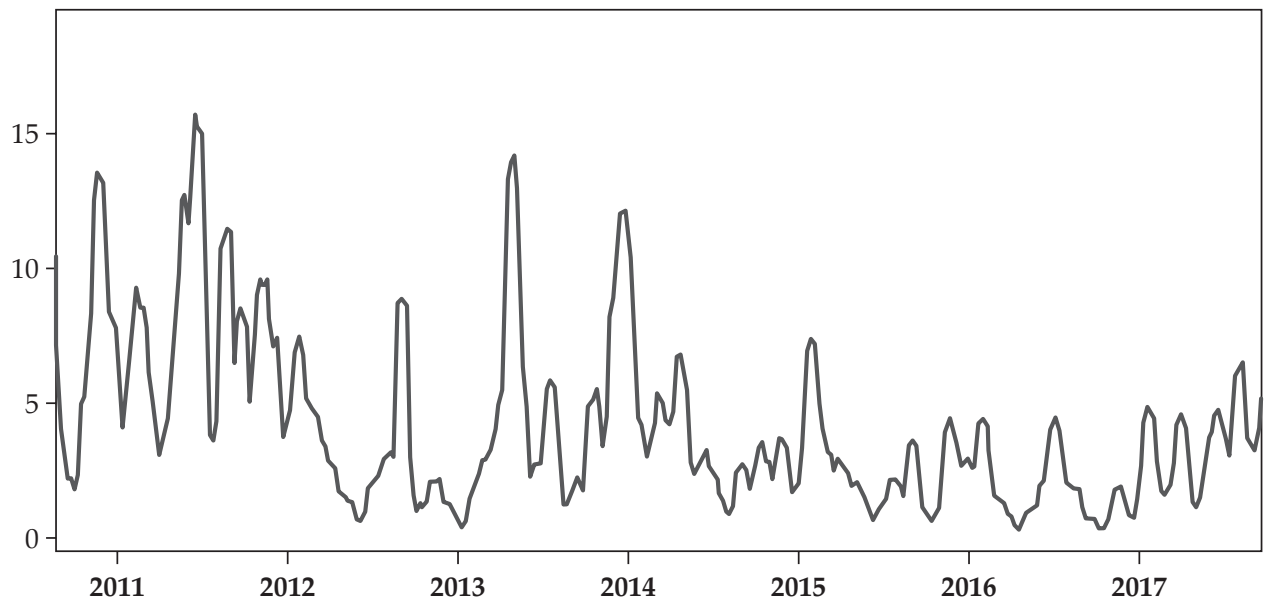

Source: https://www.quora.com

Figure 2. Volatility of Bitcoin, 2010 to 2016

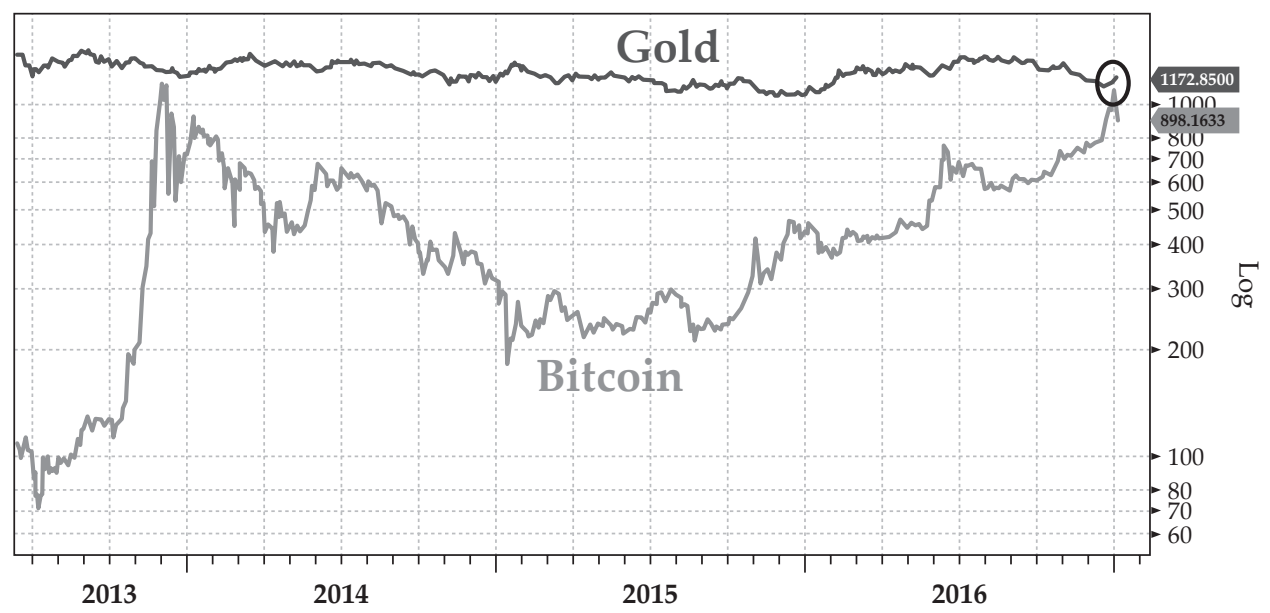

Source: http://www.zerohedge.com/news/2017-01-07/bitcoin-good-gold

Figure 3. Price Volatility of Bitcoin and Gold

Figure 3 shows the high volatility of bitcoin value compared to that of gold. Hence, it is obvious that bitcoin does not adhere well to the 'store of value' function of money.

Other issues and observations regarding bitcoin:

1. No one knows for sure who is behind the bitcoin software. It is attributed to one Satoshi Nakamoto, but no one knows if this is a true person, a group of people or what. It was indeed released as an open-source software. Hence, 
there is no one actually taking responsibility for the bitcoin 'money' or for the system as a whole.

8. How does one know or confirm that the bitcoin system does not reward its creator(s) handsomely, say periodically giving its creator(s) thousands of bitcoins free? Some might argue that this is not possible because all codes and transactions are transparent and known to all. But then,

9. How does one know that the system made available in the open source is also the system that is operating in actuality? People may argue that the codes are available for all to see, but then hidden codes etc. are all possibilities nowadays. Hence, even the statement that the maximum amount of bitcoin is capped at 21 million units only, can be disputed or yet to be seen. Basically there is no one who is truly auditing the system in the interest of all, eventhough most bitcoin users seem to believe in the authenticity and transparency of the system.

10. Bitcoin is not 'real money', i.e. it is digital money not backed by some real commodities or services. Bitcoin's value is highly volatile. Its value has also gone up tremendously over the years. Hence, there is a possibility that bitcoin value is being manipulated into a bubble. As such, the World Bank called bitcoin a Ponzi scheme.

11. Also, since bitcoin has no intrinsic value and issued privately, issuance of hundreds or even thousands of similar cryptocurrencies are expected, as have been observed. The mushrooming of such multitude of cryptocurrencies are bound create inflation on a global scale.

12. What if people get their bitcoin e-wallet hacked and stolen? There were some such cases in South Korea and Japan lately. To whom to complain? Similarly, what if the system crashes, sometime in the future? The absence of a central administrator makes all these uncertain.

The above discussion reveals that there is tremendous uncertainty (gharar) present in bitcoin and its payment system. Table 3 below summarizes the evaluation of bitcoin relative to fiat currencies and asset-backed cryptocurrencies, from Islamic perspective.

Table 3.

Comparison between Fiat Currencies and Cryptocurrencies from Islamic Perspective

\begin{tabular}{lccc}
\hline & $\begin{array}{c}\text { Usual Fiat } \\
\text { Currencies }\end{array}$ & $\begin{array}{c}\text { Bitcoin \& } \\
\text { Cryptocurrencies } \\
\text { Not Backed by Real } \\
\text { Assets }\end{array}$ & $\begin{array}{c}\text { Cryptocurrencies } \\
\text { backed by Real } \\
\text { Assets, like Gold }\end{array}$ \\
\hline $\begin{array}{l}\text { Degree of Gamble (maysir) } \\
\begin{array}{l}\text { Degree of Uncertainty } \\
\text { (gharar) }\end{array}\end{array}$ & Medium $^{11}$ & High & Low \\
$\begin{array}{l}\text { Islamic money? i.e. Does } \\
\text { it contribute to maqasid al } \\
\text { shari'ah? }\end{array}$ & No & High & Low \\
\hline
\end{tabular}




\section{FINAL CONTENTIONS AND CONCLUSION}

From the foregoing discussion and arguments, we assert the following regarding bitcoin and similar fiat cryptocurrencies:

1. The surge in bitcoin value, particularly in 2017 suggests that it is simply a bubble, a bubble that can be compared with the 'tulip bubble' of Dutch that crashed in 1637. It's a bubble that would soon burst and cause many to lose a lot of money. Of course some would profit handsomely from the whole episode. Hence, anyone buying a bitcoin now at such high price would indeed be gambling. Accordingly, there is element of gamble or maysir in current bitcoin.

2. We also contend that the surge in bitcoin price and the growing interest in cryptocurrencies worldwide is a sign that global fiat money system is fast collapsing and folding up. Bitcoin, particularly, seem to be a global choice for that alternative money the world is searching for. But nonetheless, it is still fiat.

3. Bitcoin also seem to have been designed to mimic gold. There is a possibility it was artificially propped up in 2017 to counter the recent attempt by China to use Yuan benchmarking for oil trading, backed by gold. This action by China is indeed the greatest threat to dollar's position as the internationally preferred reserve currency and to the US global hegemony.

4. The above is further accentuated by the fact that the CME Group, which owns the Chicago Mercantile Exchange and Chicago Board of Trade, launched bitcoin futures contracts, at the end of 2017.

5. Notwithstanding the above points and arguments, gold-based cryptocurrencies, like OneGram, that was launched in Dubai is acceptable as an Islamic cryptocurrencies. This is because OneGram has all the required characteristics of money compared to bitcoin, including having intrinsic value, issuer, administrator, auditor, and guarantor.

From the foregoing discussion, cryptocurrencies like bitcoin may be placed in perspective, within the wider concept of money, as summarized in Diagram 4 below:

${ }^{11}$ All fiat currencies lose value over time and ultimately become obsolete.

${ }^{12}$ Due to their fiat nature, their value tend to fluctuate greatly hence the high volatility of exchange rates between fiat currencies. 


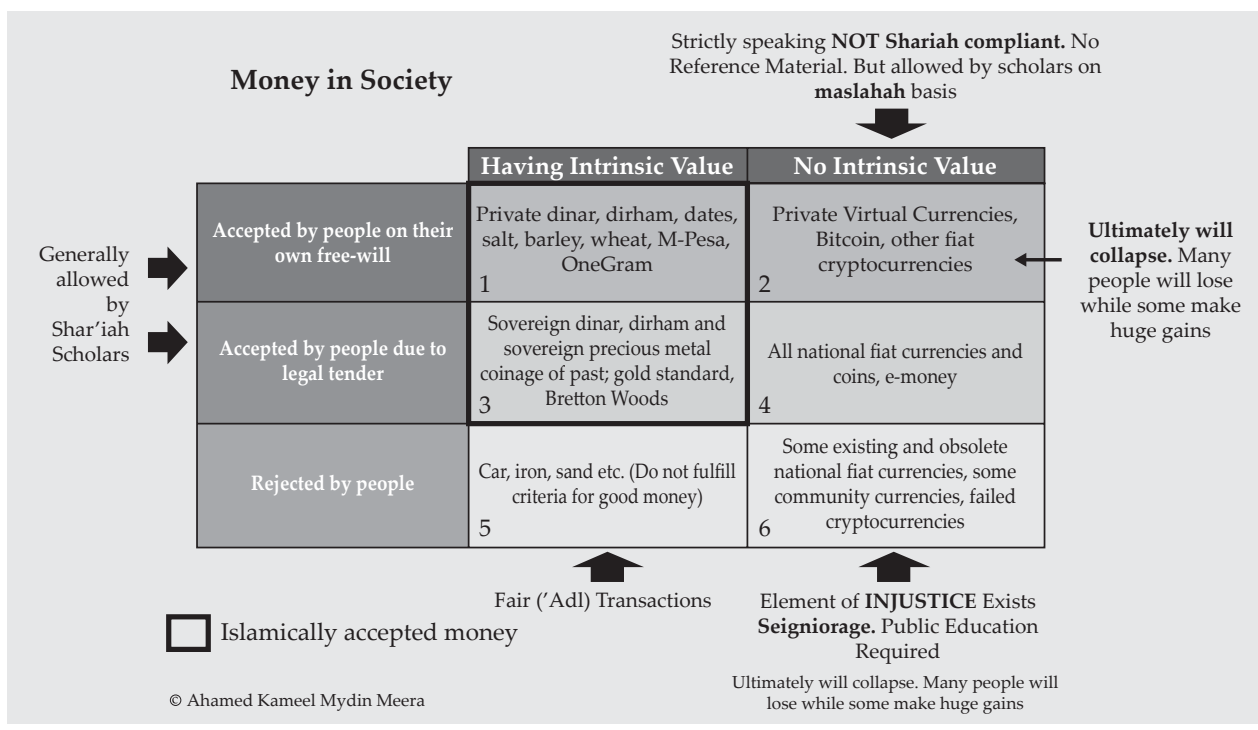

Diagram 4. Cryptocurrencies within a wider classification of money

We firstly divide money into two categories, i.e. as those having intrinsic value and those not having intrinsic value. We further subdivide into three categories, i.e. those accepted as money by people on their own free-will, those accepted due to the legal tender law, and money rejected by the people. Examples of money falling into each of the six subgroups of money are given in the respective quadrants.

Shari'ah scholars generally tend to approve any money accepted by the people irrespective of whether they accepted them on their own free-will or coerced through legal tender law or the like. This stand seems to agree with Bernard Lietaer's definition of money i.e. it is anything a society agrees to use as medium of exchange, whether willingly or coerced. Hence all money accepted by people, so long they do not involve haram items, are allowed on figh grounds, particularly on the basis of maslahah. Hence, money that falls in quadrant 1, 2, 3, and 4 in Diagram 4 are generally acceptable forms of money by shari'ah scholars and conforms to modern definition of money.

Some scholars, however, like Monzer Kahf, opine that for fiat money to be acceptable, i.e. having no intrinsic value, it must be termed legal tender by the government. In other words, the government must accept it for payment of taxes, levies, fines, etc. for a fiat money to be shari'ah permissible. This view effectively eliminates quadrant 2 , rendering only quadrants 1,3 , and 4 as shari'ah permissible money, from such scholars' perspective.

On top of that, there are scholars who reject all forms of money that do not have intrinsic value, i.e. fiat money, on the basis of their negative implications for maqasid al-shari'ah. They say the seigniorage of fiat money is at the root of substantial social, economic, political, and environmental problems of today (See for example Lietaer (2001), Meera \& Larbani (2006 and 2009)). Hence, money without intrinsic value has an element of injustice embedded in them and that 
they promote fasad on earth, while money with intrinsic value is compatible with the maqasid al-shari'ah and promote socio-economic justice ('adl). This argument effectively eliminates quadrants 2 and 4 in Diagram 4 , leaving only quadrants 1 and 3 as acceptable forms of money in Islam.

Bitcoin, together with other fiat virtual currencies fall in quadrant 2, i.e. the 'accepted on free-will' but 'no instrinsic value' region. Hence in our perspective, this money will promote socio-economic problems. Most shari'ah scholars will, however, allow them while scholars who insist on legal tender or intrinsic value will reject them ${ }^{13}$. Nevertheless, if accepted as money by the people then rules of as-sarf and riba would apply. In our opinion, the public should, however, be educated to reject such money. Bitcoin does not have a Reference Material and hence is bound to create much socio-economic problems.

On the contrary, any money having intrinsic value would promote socioeconomic justice and should be supported by both the people and the government. Such money even if forced on people through legal tender law should be acceptable since they promote socio-economic justice in society. Hence, sovereign precious metal coinage of past including the gold dinar and silver dirhams, gold standard etc. are acceptable even if these were forced upon the people. Such money will have stable value over time and space and hence able to play the 'store of value' function well. Accordingly, we contend here that any money that falls in quadrants 1 and 3 in Diagram 4 is Islamically appealing and should be promoted while those falling in other quadrants, including bitcoin, should be rejected by both the people and governments.

Money having no Reference Material will eventually lose its value and result in an utter collapse. Bitcoin is the closest example of this.

\section{REFERENCES}

Abdullah, Adam. (2016). The Islamic Currency. ICIFE.

Lietaer, Bernard. (2001). The Future of Money. Random House.

Muhammad, Marjan. (2017). Shari'ah Analysis of Cryptocurrency: Bitcoin. A Presentation Made at Shariah Fintech Forum (SFF). 8 November 2017. Hilton Hotel. Petaling Jaya.

Meera, A. K. M., and Mubasheera, Hamida. (2015). Revisiting the Concepts of Money, Profit and Interest from the Perspective of Value and Diminishing Marginal Utility. Journal of Islamic Monetary Economics and Finance, 1(1), pp. 25-53.

Meera, A. K. M., and Larbani, Moussa. (2006). Part I: Seigniorage of Fiat Money and the Maqasid al-Shari'ah:The Unattainableness of the Maqasid. Humanomics, 22(1), pp. 17-33.

Meera, A. K. M., \& Larbani, Moussa. (2009). Ownership Effects of Fractional Reserve Banking: An Islamic Perspective. Humanomics, 25, Pages: 101-116.

Nyazee, Imran K. (2008). The Concept of Riba and Islamic Banking. Advanced Legal Studies Institute.

${ }^{13}$ Recently the Grand Mufti of Egypt declared that bitcoin is banned in Islam. 
Oziev, Gapur., and Yandiev, Magomet. (2017). Cryptocurrency from Shari'ah Perspective. Presented at "The 1st Forum of CIS Scholars from Revealed Knowledge and Human Science Faculties. Jointly organized by IIIT and Public Association IDRAK. 27th-30th October. Istanbul, Turkey. 
This page is intentionally left blank 